\title{
Educación Estadística, Democracia y Empoderamiento de los Ciudadanos
}

\author{
Joachim Engel \\ engel@ph-ludwigsburg.de \\ https://orcid.org/0000-0002-8251-6670 \\ Ludwigsburg University of Education \\ Ludwigsburg, Alemania \\ Jim Ridgway \\ jim.ridgway@durham.ac.uk \\ University of Durham \\ Durham, UK \\ Florian Weber Stein \\ Florian.weber-stein@ph-ludwigsburg.de \\ Ludwigsburg University of Education \\ Ludwigsburg, Alemania
}

Recibido: 01/09/2020 Aceptado: 02/02/2021

\section{Resumen}

La democracia prospera en argumentos basados en evidencia. La desinformación e ignorancia son amenazas para nuestra forma de vida. La democracia y ciudadanía activa necesitan ciudadanos bien informados que puedan comprender los problemas sociales, debatirlos, participar activamente en la vida cívica y contribuir a la toma de decisiones públicas. En respuesta a estos retos, en este documento se introduce la Estadística Cívica, conceptualizada por el proyecto internacional ProCivicStat. La Estadística Cívica se centra en la comprensión y reflexión crítica de la información estadística sobre la sociedad, proporcionada en los medios de comunicación, las oficinas de estadística y otros organismos. Describimos las características específicas de la información que los ciudadanos reciben sobre temas cívicos y las habilidades, facetas y herramientas necesarias para comprender la información estadística sobre la sociedad. Examinamos los problemas que son esenciales para promover los cambios necesarios para introducir la enseñanza de la Estadística Cívica en los planes de estudio y la educación de los docentes, con la finalidad de para empoderar a los ciudadanos para que participen en el razonamiento basado en datos sobre temas candentes en la sociedad. Se proporcionan ejemplos del monitoreo del cambio climático y la medida de la calidad democrática.

Palabras clave: Alfabetización estadística, Datos abiertos, Pensamiento multivariado, Democracia.

\section{Educação Estatística, Democracia e Capacitação do Cidadão}

\section{Resumo}

A democracia prospera em argumentos baseados em evidências. A desinformação e a ignorância são ameaças ao nosso modo de vida. A democracia e a cidadania ativa precisam de cidadãos bem informados que possam compreender questões sociais importantes, discuti-las, participar 
ativamente da vida cívica e contribuir para a tomada de decisões públicas. Em resposta a esses desafios, este documento apresenta as Estatística Cívica, conceituadas pelo projeto internacional ProCivicStat. Estatística Cívica se concentra na compreensão e reflexão crítica da informação estatística sobre a sociedade, disponibilizada nos meios de comunicação, gabinetes de estatística e outras organizações. Descrevemos as características específicas das informações que os cidadãos recebem sobre questões cívicas e as habilidades, facetas e ferramentas necessárias para compreender as informações estatísticas sobre a sociedade. Examinamos as questões essenciais para promover as mudanças necessárias para introduzir o ensino de Estatística Cívica nos currículos e na formação de professores, com o objetivo de capacitar os cidadãos a se engajarem em raciocínios baseados em dados sobre tópicos quentes na sociedade. Exemplos de monitoramento de mudanças climáticas e medição democrática da qualidade são fornecidos.

Palavras chave: Literacia estatística, dados abertos, pensamento multivariado, democracia, cidadania

\title{
Statistics Education, Democracy and Citizen's Empowerment
}

\begin{abstract}
Democracy thrives on arguments based on evidence. Misinformation and ignorance are threats to our way of life. Democracy and active citizenship need well-informed citizens who can understand social issues, discuss them, actively participate in civic life, and contribute to public decision-making. In response to these challenges, this document introduces Civic Statistics, conceptualized by the international project ProCivicStat. Civic Statistics focuses on the understanding and critical reflection of statistical information about society, provided by the media, statistical offices and other organizations. We describe the specific characteristics of the information that citizens receive on civic issues and the skills, facets, and tools necessary to understand statistical information about society. We examine the issues that are essential to promote the changes needed to introduce civic statistics teaching into curricula and teacher education, with the aim of empowering citizens to engage in data-informed reasoning about burning issues in society. Examples of climate change monitoring and measuring the quality of democracy are provided.
\end{abstract}

Keywords: Statistical Literacy, open data, multivariate thinking, democracy, citizenship

\section{Introducción}

Los medios digitales y la accesibilidad de los datos están cambiando nuestro acceso a la información y dando forma al discurso político. Diferentes organizaciones han recopilado una gran cantidad de información que cualquiera puede utilizar para informar y debatir, desde el trabajo de las Naciones Unidas sobre los Objetivos de Desarrollo Sostenible, hasta la medición del progreso social, pasando por las Oficinas Nacionales de Estadística que recopilan información sobre empleo, ingresos y migración, hasta las Organizaciones No Gubernamentales 
(ONG) que monitorean el cambio climático o la salud de los ciudadanos.

La tecnología proporciona herramientas poderosas para la visualización de datos, y ofrecen a los ciudadanos el potencial de explorar fuentes de información valiosas por sí mismas. La World Wide Web es una poderosa influencia en el acceso del público a datos abiertos y a documentos gubernamentales, tácticas y contenido de las campañas políticas, comportamiento de los votantes y esfuerzos de los activistas para hacer circular sus mensajes. La explosión de las redes sociales está impulsando direcciones nuevas e imprevistas en la e-democracia y la eparticipación, como una mayor demanda de democracia directa y nuevas ideas para involucrar a los ciudadanos al servicio de la democracia directa (Engel, 2017).

En contradicción con estas nuevas oportunidades, existe un creciente desdén por el conocimiento fáctico en el discurso público, que es acelerado por la proliferación de noticias falsas en las redes sociales, difundidas sin filtros de verificación de los hechos. La toma de decisiones basada en la evidencia se enfrenta a una crisis existencial. Los periodistas responsables son retratados como enemigos del pueblo, las agencias gubernamentales no pueden reportar datos, sin comprobar que puedan contradecir el dogma político (por ejemplo, sobre el cambio climático). La disponibilidad inmediata de recursos para crear videos manipulados falsos (deep fake) plantea otra amenaza, de naturaleza diferente. En un clima de ansiedad, confusión y nostalgia por un pasado idealizado, como apunta la expresidenta del Consejo Europeo de Investigación Helga Nowotny (2016), prevalecen las emociones incontroladas que implican una mala forma de afrontar la incertidumbre, en marcado contraste con los métodos de la ciencia y la investigación libre.

Siguiendo el término Alfabetización estadística, la asociación estratégica internacional ProCivicStat (con la participación de las universidades de Durham, Haifa, Ludwigsburg, Paderborn, Porto y Szeged, del Reino Unido, Israel, Alemania, Hungría y Portugal) ha conceptualizado una subdisciplina llamada Estadística Cívica, que se centra en obtener significado a partir de datos que informan sobre los procesos sociales, el bienestar social y económico y la realización de los derechos civiles. Comprender estos temas es de crucial importancia para la participación cívica en las sociedades modernas, cuyo funcionamiento, a menudo, se basa en datos complejos y multivariados, cuya interpretación y desarrollo requieren conocimientos que generalmente no se enseñan en la educación habitual en matemáticas y estadística, y mucho menos en política o estudios sociales. 
El propósito de este artículo es subrayar la necesidad de habilidades estadísticas para la participación informada en sociedades democráticas (Sección 2), dar una breve introducción a lo que entendemos por Estadística Cívica (Sección 3) y resaltar las características específicas de los mensajes estadísticos sobre la sociedad. como los ciudadanos ven, leen o escuchan sobre mensajes con contenido estadístico en los medios de comunicación, discusiones privadas o en el discurso público. En un segundo paso, nos enfocamos en las herramientas, habilidades y competencias necesarias para comprender críticamente las estadísticas cívicas con el fin de involucrarnos con los problemas sociales o económicos subyacentes, ilustrados con ejemplos sobre el cambio climático y medición de la calidad de la democracia (Sección 4).

La Sección 5 presenta un ejemplo extenso e informa sobre una experiencia docente concreta en un seminario conjunto para estudiantes de matemáticas y ciencias políticas que se preparan para ser profesores de secundaria. La Sección final 6 discute las implicaciones curriculares para la implementación de la Estadística Cívica en los planes de estudios de secundaria y post secundaria. En síntesis, este artículo tiene como objetivo ofrecer una breve introducción a las características y requisitos de competencia de la Estadística Cívica, presentar ejemplos típicos y señalar las implicaciones curriculares. Para el lector interesado, los extensos recursos originados en el proyecto ProCivicStat que consisten en materiales de enseñanza, conjuntos de datos, representaciones conceptuales y mucho más están disponibles gratuitamente a través del sitio web http://iase-web.org/islp/pcs.

\section{La democracia necesita ciudadanos con conocimientos estadísticos}

Para que la democracia funcione, los ciudadanos deben conocer y comprender críticamente la evidencia cuantitativa sobre cuestiones clave relacionadas con el bienestar social, económico y sanitario y el logro de los derechos civiles. Por ejemplo, en una sociedad que busca mantenerse al día con las promesas de equidad y justicia para todos, las preguntas sobre si las mujeres, las minorías o las personas con discapacidades se encuentran en desventaja en sus opciones profesionales, salarios o acceso a la educación [superior] o los servicios, deben ser juzgadas en gran medida cuantitativamente y requieren conocimientos estadísticos. La toma de decisiones sólida basada en la evidencia en la vida privada y pública requiere habilidades de razonamiento cuantitativo y actitudes positivas (igualmente importantes), es decir, la voluntad de trabajar con datos estadísticos.

4 Revista Paradigma, Vol. XLII, Nro. Extra1: Educación Estadística, marzo de 2021 / 01 - 31 
En un mundo cada vez más complejo, la opinión de los ciudadanos es un recurso fundamental para los responsables políticos a nivel nacional y local, y la implementación de decisiones difíciles sobre temas sociales controvertidos depende del consentimiento y apoyo de los ciudadanos. A menos que los ciudadanos comprendan y participen ellos mismos en la decisión, la confianza en la toma de decisiones políticas se pierde fácilmente (OECD, 2009). La participación ciudadana puede apoyar el funcionamiento efectivo de la democracia, la legitimidad del gobierno, la implementación exitosa de políticas y el logro de resultados sociales. La falta de compromiso puede conducir a malas decisiones y alienación. Una ciudadanía ilustrada que está facultada para estudiar hechos basados en evidencia y tiene la capacidad de administrar, analizar y pensar críticamente sobre los datos es el mejor remedio para un mundo impulsado por noticias fabricadas o que desconocen los hechos. Se necesitan habilidades de Estadística Cívica para una participación informada en sociedades democráticas. La Estadística Cívica se basa en la evaluación y la reflexión críticas y su conocimiento es un remedio esencial para enfrentarse a las noticias y afirmaciones falsas.

Alcanzar el objetivo de la participación ciudadana implica la necesidad de dotar a los estudiantes y [jóvenes] adultos con los conocimientos, habilidades y actitudes necesarias para comprender los datos y comprometerse con las estadísticas involucradas. Los planes de estudios actuales, en la escuela secundaria y en la universidad, no está alineado con las necesidades de ciudadanía y no está orientado a permitir que los estudiantes transfieran las habilidades que adquieren a sus deberes como ciudadanos comprometidos. La buena participación ciudadana apoya el funcionamiento efectivo de la democracia, la legitimidad del gobierno, la implementación exitosa de políticas y el logro de resultados sociales. Las malas prácticas de participación pueden conducir a malas decisiones y a la desvinculación de los ciudadanos (Brodie et al, 2011).

\section{3. ¿Qué es la Estadística Cívica?}

Hasta hace poco, y en muchas partes del mundo incluso hoy en día, el verdadero estado de la sociedad se mantenía como un alto secreto. El paternalismo es más antiguo que el pensamiento estadístico y los datos secretos son más antiguos que los datos abiertos. Los enemigos tradicionales de la alfabetización estadística han sido los gobiernos autoritarios y la falta de educación pública. Pero para que la democracia funcione, los ciudadanos deben estar 
bien informados y ser capaces de razonar basándose en hechos.

Existe una larga historia de defensa del papel de la evidencia en la promoción de la justicia social. Ya en 1792, Condorcet (1994/1792), matemático y filósofo francés durante la época de la Revolución Francesa, defendía la importancia de informar a los ciudadanos sobre la gobernanza y presentarles evidencias sobre el estado de la sociedad para concienciarles sobre las injusticias y las estructuras sociales de las desigualdades. Creía en el savoir liberateur, el conocimiento que permitiría a las personas liberarse de la opresión social. El Atlas político y comercial de William Playfair (2005/1786) es una de las primeras publicaciones diseñadas para hacer que la evidencia compleja fuese accesible a una amplia audiencia; John Snow y Florence Nightingale utilizaron potentes representacionies gráficas para abordar los problemas asociados con las enfermedades; el trabajo de Otto Neurath (2010) sobre isotipos durante la década de 1930 se propuso establecer un lenguaje gráfico universal para familiarizar al público con la comprensión de los datos estadísticos y con el concepto de riesgo. Sin embargo, una buena educación en estadística sigue siendo la excepción y no la regla en la mayoría de los países, lo que resulta en un analfabetismo estadístico colectivo (Gigerenzer, 2014).

Antes de la década de 1830, las estadísticas sobre los ciudadanos se consideraban en gran medida secretos de estado y se mantenían selladas deliberadamente. Fueron la clave para recaudar impuestos y reclutar soldados y para el éxito económico. Hoy, la mayoría de los datos están abiertos al público; el problema actual es cómo enseñar a todo el mundo a distinguir los datos fiables de las noticias falsas.

La Estadística Cívica se centra en comprender la información estadística sobre la sociedad proporcionada por los medios de comunicación, las oficinas de estadísticas y otros organismos. Su comprensión es necesaria para la participación en sociedades democráticas, pero implica datos que a menudo son abiertos, oficiales, de naturaleza multivariada y / o dinámicos, y generalmente no son el núcleo de la instrucción estadística regular. La Estadística Cívica se refieren a las habilidades necesarias para comprender la evidencia sobre los fenómenos sociales clave que impregnan la vida cívica, como la migración, el desempleo, la (des) igualdad social, los cambios demográficos, el racismo, la delincuencia, la pobreza, el acceso a los servicios, la salud, el cambio climático, la educación, derechos humanos y muchos otros. La Estadística Cívica se sitúa en la intersección de la estadística y la educación cívica / ciencias sociales (Figura 1) y tiene una misión educativa distinta de la de estas otras materias. 
Figura 1. Estadística Cívica como intersección de la estadística, las ciencias sociales y la educación.

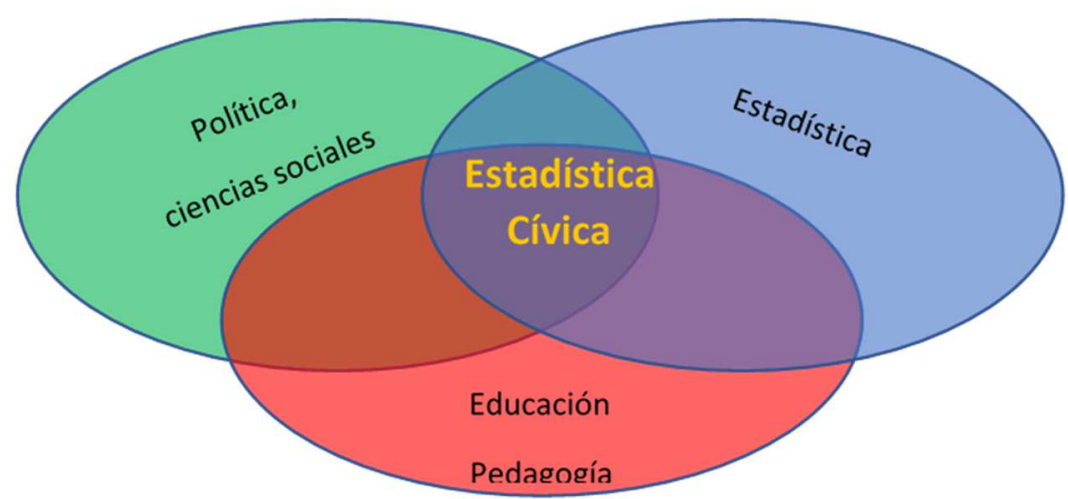

Fuente: ProCivicStat Partners (2018), p. 19

Mientras que la alfabetización estadística como competencia básica apunta a la capacidad general (ver, por ejemplo, Gal 2002 o Wallman, 1993,) para evaluar datos estadísticos de todo tipo de contextos, la Estadística Cívica se centra en cuestiones de relevancia para la sociedad. En un enfoque relacionado, Steen (2001, pág. 2) caracterizan explícitamente el significado del conocimiento matemático y estadístico dentro de la democracia como alfabetización cuantitativa al enfatizar que

los ciudadanos con conocimientos cuantitativos necesitan saber más que fórmulas y ecuaciones. Necesitan una predisposición para mirar el mundo a través de los ojos, para ver los beneficios (y riesgos) de pensar cuantitativamente sobre problemas comunes y abordar problemas complejos con confianza en el valor de un razonamiento cuidadoso. La alfabetización cuantitativa empodera a las personas al brindarles herramientas para pensar por sí mismas, para hacer preguntas inteligentes a los expertos y enfrentar la autoridad con confianza.

En la enseñanza de habilidades cuantitativas básicas, el contenido es inseparable de la pedagogía y el contexto es inseparable del contenido (Steen, 2001). Las matemáticas y la estadística son una parte clave para avanzar hacia estructuras sociales más democráticas, participativas y socialmente justas (Skovsmose, 1994). La Estadística Cívica está relacionada con los conceptos de alfabetización estadística crítica (Weiland, 2017) y los combina con conceptos modernos de enseñanza-aprendizaje de la estadística (por ejemplo, Ben Zvi \& Garfield, 2004). Los contextos ya no son solo un pretexto para aprender métodos estadísticos, sino que las reflexiones sociopolíticas basadas en el conocimiento cuantitativo son la clave para 
construir una ciudadanía crítica en la que los estudiantes ya no sean observadores del mundo, sino participantes y transformadores de las crisis sociales (Skovsmose, 1994 ). La alfabetización es más que la capacidad de leer, escribir o hacer cálculos elementales y abarca la competencia para interpretar la vida social (Freire, 2014). En el proyecto ProCivicStat, se eligió el término Estadística Cívica para resumir todas estas perspectivas de manera concisa.

Ya enfoques anteriores (Borovcnik y Ossimitz 1987; Fischer, 1984) han vinculado el análisis exploratorio de datos con objetivos de educación política y procesos de concienciación. López-Martín, Batanero y Arteaga (2016) proponen investigar los datos de esperanza de vida y desigualdad de género para aumentar el interés en los datos sociales y el análisis de datos entre los futuros profesores de secundaria en España. Lesser (2007) describe la estadística como una gramática de la justicia social y analiza cómo tratar una serie de conceptos estadísticos en el contexto de los problemas de justicia social. El proyecto ProCivicStat desarrolló un marco teórico para la Estadística Cívica, identificó habilidades específicas para comprender las estadísticas sobre la sociedad y desarrolló numerosos materiales didácticos concretos y de acceso abierto que ofrecen muchas oportunidades al acceder a registros existentes y herramientas poderosas y diseñadas educativamente para proporcionar más información en profundidad y análisis de datos que los enfoques anteriores.

Los datos estadísticos que informan sobre la política social son bastante complejos: suelen ser multivariados, datos agregados y sistemas de indicadores son frecuentes; las variables interactúan y los datos pueden ser críticos, en cuanto al tiempo. Más allá de esto, los ciudadanos deben hacer más que comprender los datos: deben ver las implicaciones para la sociedad y la política, lo que requiere un conocimiento contextual sobre el estado de la sociedad. Los estudiantes deben adoptar una actitud inquisitiva y saber qué preguntas hacer sobre la naturaleza, las limitaciones o la credibilidad de las diferentes fuentes de datos, mensajes estadísticos y conclusiones. Los problemas que se abordan en las estadísticas cívicas rara vez tienen una respuesta correcta o incorrecta simple y clara, a diferencia de los problemas de las matemáticas escolares tradicionales y de los cursos de introducción a la estadística. Los estudiantes deben considerar cuánta evidencia proporcionan los datos para las afirmaciones que se realizan, explorar formas de triangular el problema y obtener información a través de diferentes enfoques, representaciones alternativas y explorar conjuntos de datos relacionados.

\section{Características y desafíos de las estadísticas cívicas}


Las estadísticas sobre fenómenos sociales a menudo tienen características especiales y plantean demandas específicas a los ciudadanos que intentan comprender los mensajes estadísticos. Aquí describimos sus principales características y desafíos. Más detalles, incluidos ejemplos, se encuentran en varias publicaciones de ProCivicStat (ProCivicStat2018), y en un libro a punto de publicarse (Ridgway, 2021) o (más resumido, en español) en Engel (2019).

Los datos estadísticos que informan la política social tienen características específicas. Primero, describimos la naturaleza de la Estadística Cívica, que los ciudadanos ven, leen o escuchan en mensajes de contenido estadístico en los medios, discusiones privadas o en el discurso público. En un segundo lugar, nos enfocamos en las herramientas, habilidades y competencias necesarias para comprender críticamente las estadísticas cívicas con el fin de involucrarnos con los problemas sociales o económicos subyacentes.

La información estadística sobre la sociedad suele ser bastante compleja. Los datos suelen ser multivariados, frecuentemente con datos agregados y sistemas de indicadores y variables que interactúan. Los datos pueden depender del tiempo, es decir, pueden cambiar rápidamente y medirse con diferentes métodos a lo largo del tiempo. Existe un conjunto básico de habilidades asociadas con la lecto-escritura y la aritmética que son esenciales para el funcionamiento en la sociedad, tales como habilidades de lectura, comprensión de argumentos, lectura de gráficos y manejo de porcentajes. Adicionalmente, los ciudadanos deben hacer más que comprender los datos: deben ver las implicaciones para la sociedad y las políticas. Esto requiere conocimiento sobre los procesos de generación de conocimiento y las formas de representar y modelar situaciones, junto con ideas que se enseñan comúnmente en los cursos de estadística, como el sesgo de la muestra y el tamaño del efecto. También requiere conocimiento contextual sobre el estado de la sociedad. La Estadística Cívica tienen como objetivo empoderar a los ciudadanos y a los responsables de la formulación de políticas al abordar los problemas centrales asociados con la toma de decisiones basada en evidencia. Esto incluye: desarrollar competencia para cuestionar la procedencia y calidad de los datos; comprender los usos y abusos de una amplia gama de métodos para presentar y analizar datos sociales de una variedad de fuentes; conocer las formas de representar y modelar situaciones; comprender el riesgo.

\section{Ejemplo: comprender la evidencia relacionada con el cambio climático}


Está claro que el contexto social es un enfoque adecuado para este problema: un aumento en el nivel del mar y la destrucción de tierras fértiles conducirían a la migración masiva y los desafíos asociados. Los datos a menudo están integrados en textos enriquecidos; como se ilustra a lo largo de esta sección. La siguiente cita está tomada de Eckstein, Künzel, Schäfer, \& Winges, $(2019$, p.5).

La población mundial se enfrenta a la realidad del cambio climático; en muchas partes del mundo esto se manifiesta en una mayor volatilidad de los fenómenos meteorológicos extremos. Entre 1999 y 2018, unas 495 000 personas murieron en todo el mundo y se incurrieron en pérdidas de 3,54 billones de dólares estadounidenses (en PPA) como resultado directo de más de 12000 fenómenos meteorológicos extremos

En este tipo de mensajes es necesario explorar las posibles causas. En este contexto, podemos identificar dos preguntas separadas sobre la causalidad: una se refiere a las causas de los eventos climáticos extremos (por ejemplo, ¿se pueden atribuir los eventos climáticos al calentamiento global?); la otra se refiere al calentamiento global en sí (¿es atribuible a acciones humanas?). La Sociedad Meteorológica Estadounidense publica informes anuales sobre la explicación de eventos extremos. La siguiente cita se tomó de su informe de 2019 (https://www.ametsoc.org/ams/index.cfm/publications/bulletin-of-the-american-meteorologicalsociety-bams/explaining-extreme-events-from-a-climate-perspective/) y realiza dos afirmaciones causales: se podría pedir a los estudiantes que exploren la plausibilidad de cada una.

La desertizante sequía de Four Corners, las intensas olas de calor en la península ibérica y en el noreste de Asia, las precipitaciones excepcionales en los estados del Atlántico medio y el nivel récord de hielo marino en el mar de Bering fueron los eventos climáticos extremos de 2018 más probablemente debidos al cambio climático causado por el hombre, según una nueva investigación publicada hoy en el Bulletin of the American Meteorological Society (BAMS). La octava edición del informe, Explicación de los eventos extremos en 2018 desde una perspectiva climática, presenta 21 nuevos análisis revisados por pares sobre el clima extremoen cinco continentes y un mar durante 2018. Presenta la investigación de 121 científicos de 13 países que analizan observaciones y simulaciones de modelos para determinar si el cambio climático puede haber influido en determinados eventos extremos y en qué medida.

Es obvio que el cambio climático considera fenómenos multivariados que abarcan eventos físicos, como la acidificación de los océanos e incendios forestales en Alaska y Siberia, 
las actividades humanas, como la muerte y la migración, y eventos ecológicos como la destrucción del hábitat y la pérdida de especies. Las medidas orientadas hacia estas problemáticas y su puesta en funcionamiento plantean serios desafíos; por ejemplo, ¿cómo se podría medir la gravedad de los incendios forestales en Australia? ¿Número de incendios? ¿Casas destruidas? ¿Muertes de personas y animales? ¿Disminución de la actividad económica? ¿Área desolada?

Los sistemas de indicadores son frecuentes. Por ejemplo, Germanwatch ha desarrollado un Índice de Riesgo Climático Global, que se utiliza para clasificar los países en función de: número de muertos, muertes por cada 100000 habitantes, pérdidas absolutas en la paridad del poder adquisitivo y pérdidas por unidad de PIB. Ponderado $(1 / 6 ; 1 / 3 ; 1 / 3 ; 1 / 6)$ respectivamente. Al comienzo de su informe de 2020 (Eckstein et al.2019, p.3), advierten:

Sin embargo, el índice no debe confundirse con un puntaje integral de vulnerabilidad climática. Representa una pieza importante en el rompecabezas general de los impactos relacionados con el clima y las vulnerabilidades asociadas. El índice se centra en los fenómenos meteorológicos extremos, pero no tiene en cuenta procesos importantes de desarrollo lento, como el aumento del nivel del mar, el deshielo de los glaciares o mares más ácidos y cálidos. Se basa en datos pasados y no debe utilizarse como base para una proyección lineal de los impactos climáticos futuros. Más específicamente, deben extraerse conclusiones de no demasiado largo alcance para los debates políticos sobre qué país o región es más vulnerable al cambio climático.

El cambio climático también ilustra la amplia variedad de métodos de recopilación de datos utilizados para abordar problemas complejos. Los ejemplos incluyen imágenes de satélite, sensores en tierra y mar, y datos de encuestas sobre la actividad humana. Del mismo modo, las discusiones sobre el cambio climático son ricas en visualizaciones innovadoras. Estos incluyen video (mapeo de la extensión y edad del hielo polar, o imágenes de desastres naturales), una amplia gama de mapas de coropletas, junto con series de tiempo interactivas más convencionales.

De manera similar, los debates sobre el cambio climático son ricos en visualizaciones innovadoras. Estos incluyen video (mapeo de la extensión y edad del hielo polar, o imágenes de desastres naturales), una amplia gama de cartogramas, junto con series de tiempo interactivas más convencionales. La Figura 2 muestra una visualización de datos innovadora tomada de la web que se puede utilizar como punto de partida para la exploración de cuestiones sustantivas 
y como foco para la introducción de ideas estadísticas importantes. (http://www.climate-labbook.ac.uk/files/2016/06/icevol.gif)

Figura 2. Volumen del hielo marino del Ártico en función del tiempo

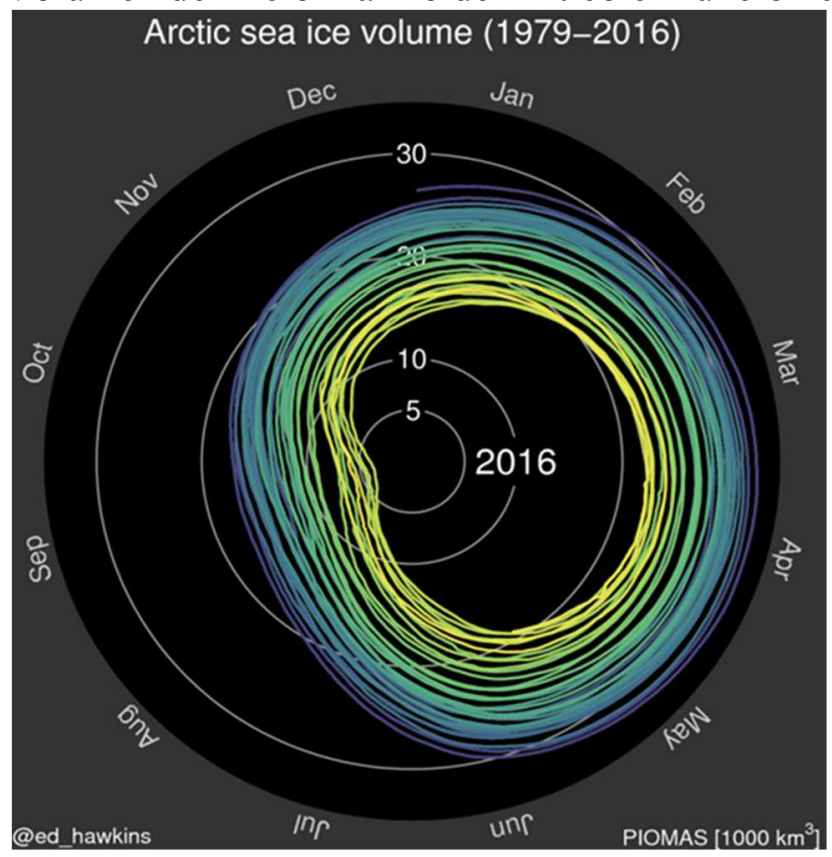

Fuente: http://www.climate-lab-book.ac.uk/files/2016/06/icevol.gif

Este gráfico proviene del Polar Science Center de la Universidad de Washington, cuyas observaciones se recopilan en el Registro Unificado de Datos Climáticos sobre el espesor del hielo marino. El gráfico puede apoyar el desarrollo de algunas ideas estadísticas clave. Ofrece una oportunidad para que los estudiantes interpreten la información gráfica presentada de una manera que tal vez no hayan visto antes. Trazar los datos mensuales en una pantalla circular reduce el problema de separar los cambios estacionales de los cambios a largo plazo. A los estudiantes simplemente se les puede preguntar qué ven: hay marcadas tendencias estacionales, una gran variabilidad en los datos interanuales y una disminución en el volumen de hielo marino a lo largo del tiempo. ¿Se puede provocar a los estudiantes a buscar otras pruebas: ¿está disminuyendo el volumen de hielo antártico? ¿Qué pasa con los glaciares de todo el mundo? ¿O la temperatura del mar en diferentes lugares? Estas preguntas provocan reflexiones sobre el muestreo y la representatividad, como las siguientes:

- P1: ¿Qué variables se visualizan?

- P2: ¿Qué tendencia percibe dentro de cada año?

- P3: ¿Qué tendencia percibe a lo largo de los años? 
- P4: ¿Se está calentando nuestro planeta?

Se puede preguntar a los estudiantes sobre sus predicciones para el futuro: ¿Cuándo habrá poco o ningún hielo ártico en los meses de verano? ¿Pueden ofrecer una estimación acotada? Esto los lleva a los dominios del modelado, que se pueden abordar con diferentes niveles de sofisticación. ¿Es posible que se aplique un modelo lineal simple? (Probablemente no). ¿Qué factores pueden acelerar el cambio? ¿Hasta qué punto creen que el fenómeno puede predecirse con algún grado de precisión (las estimaciones anteriores casi siempre han subestimado la velocidad del cambio)? Después de describir lo que los ciudadanos escuchan, ven o leen cuando se enfrentan a mensajes estadísticos en los medios de comunicación, discusiones privadas y discursos públicos, pasamos a la pregunta: ¿Qué habilidades y competencias se necesitan para que puedan comprender críticamente las estadísticas cívicas que ven / leen / escuchan, y se comprometen con los problemas sociales o económicos subyacentes?

Las Estadística Cívica no trata simplemente del dominio de técnicas. Implican hábitos mentales, la voluntad de interactuar con los datos, y procesos relacionados, la capacidad de razonar, buscar y comunicarse con evidencia numérica. Nicholson, Gal y Ridgway (2018) describen once facetas de la alfabetización estadística que sustentan la capacidad de involucrarse con problemas sociales, es decir, de comprender las estadísticas cívicas. La faceta central es el significado de la política social; todos los demás aspectos de la alfabetización estadística contribuyen a esta faceta. En el centro, como punto de partida y final de cualquier compromiso con las estadísticas cívicas, se encuentra la evaluación crítica y la reflexión de un tema socialmente significativo. Obviamente, conocimientos estadísticos generales y específicos, por ejemplo, a las representaciones y modelos y la metodología de la recopilación de datos es tan necesaria como el conocimiento contextual social o socioeconómico. Para poder activar o adquirir conocimientos e interés especiales existentes en temas cívico-estadísticos, es posible que aún se requieran ciertas habilidades en la búsqueda de datos y en la preparación y limpieza de datos con software y hardware adecuados. Además, las habilidades numéricas básicas (por ejemplo, comprensión de porcentajes, nociones razonables de magnitudes numéricas) son tan básicas como la lectura apropiada y la comprensión de textos, así como las habilidades para comunicar adecuadamente posiciones y conclusiones elaboradas.

El marco conceptual desarrollado por Nicholson et al. (2018) describe las bases de 
conocimiento, las habilidades, los procesos habilitadores y las disposiciones y actitudes que, en conjunto, se necesitan si esperamos que los alumnos comprendan críticamente y se comprometan con las estadísticas cívicas. Todas estas 11 facetas se pueden aprender, es decir, se pueden cambiar o 'mejorar' en el aula. Por tanto, son la base para el desarrollo de métodos de enseñanza y materiales curriculares que puedan ayudar a los procesos de enseñanza / aprendizaje enfocados en la Estadística Cívica.

Las 11 facetas se pueden organizar en tres dimensiones o grupos (ver Figura 3):

- Compromiso y acción, que comprende: Significado para la sociedad y la política; Evaluación crítica y reflexión; y Disposiciones

- Conocimiento, que comprende: Estadísticas y riesgo; Representaciones, patrones y modelos; Metodología y procesos de indagación; Extensiones en estadísticas oficiales; y conocimiento cívico contextual

- Procesos habilitadores, que comprenden: TIC y búsqueda; Núcleo cuantitativo; y alfabetización y comunicación

Figura 3. Facetas de Estadística Cívica

\section{ProCivicStat marco conceptual}

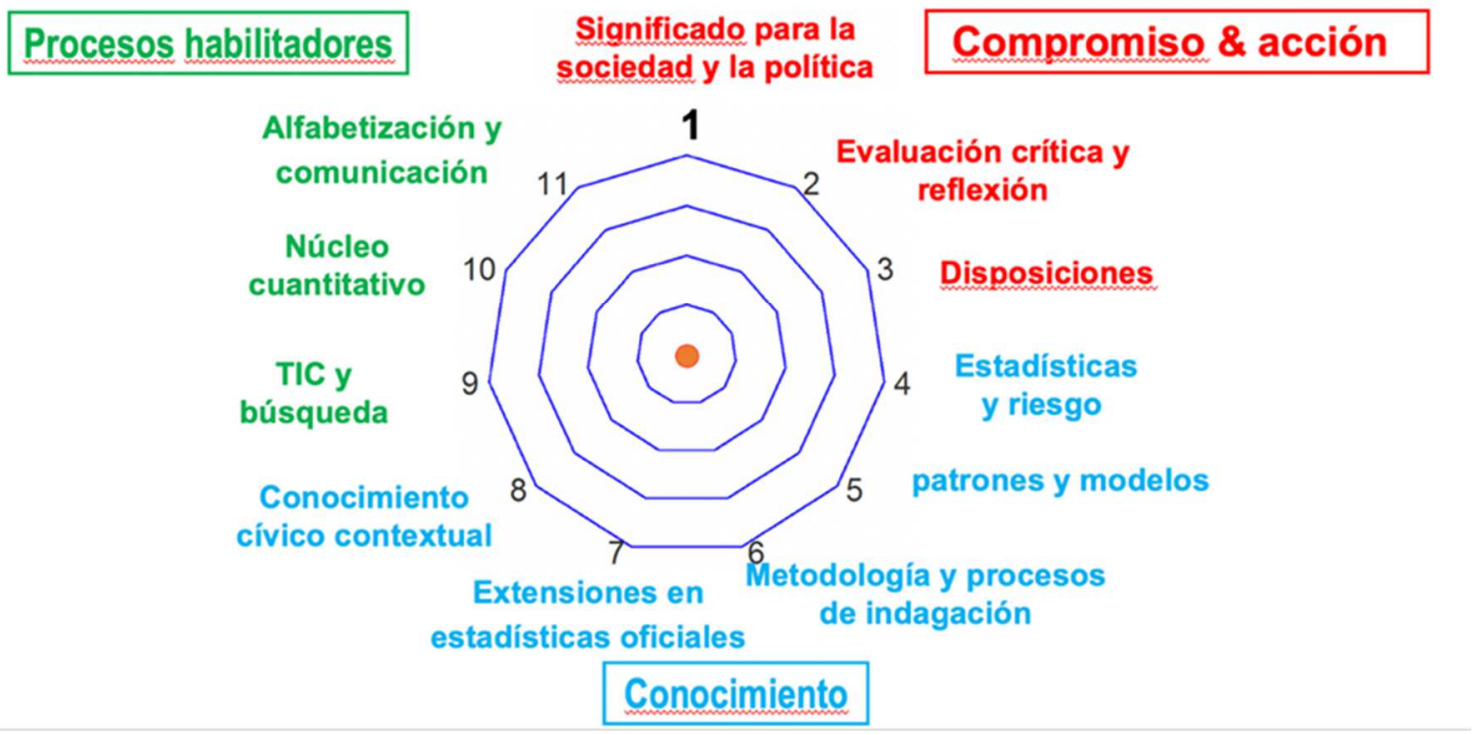

Fuente: Nicholson, Gal \& Ridgway (2018), p 6

Basádose en la representación en la Figura 3, Nicholson et al. (2018) también desarrollaron una herramienta de gráfico polar para analizar tareas y otras actividades que exigen habilidades de Estadística Cívica. Para obtener más detalles y varios ejemplos resueltos, se 
puede consultar Ridgway, Nicholson y Gal (2017).

\section{Un ejemplo de material de enseñanza y aprendizaje: Calidad de la democracia}

Las competencias presentadas en la Sección 4 brindan una visión integral de los múltiples requisitos en el contexto de la Estadística Cívica, que establece metas ambiciosas, incluso para la educación universitaria. Sin embargo, parte de estas facetas ya se pueden abordar en el bachillerato después de alguna adaptación y reducción didáctica. El proyecto Strengthening Data Literacy across the Curriculum ha desarrollado prototipos de módulos de estadísticas con un enfoque de justicia social para los estudiantes estadounidenses que deben cursar un cuarto año de matemáticas en la escuela secundaria y que no están interesados en tomar un curso de nivel avanzado (Louie, Chance, Roy, Fagan, \& Stiles, 2020). Un módulo se centra en la desigualdad de ingresos de EE. UU, y otro se centra en la inmigración a EE. UU. En ProCivicStat, creamos 41 unidades didácticas en varios idiomas (inglés, alemán, portugués y húngaro) para la enseñanza en escuelas y universidades, la mayor parte de las cuales también se han probado en seminarios. Todos los materiales tienen un tema o pregunta de relevancia social como punto de partida y están diseñados para un rango de 3 a 8 horas de clase. La amplia gama de temas cubiertos incluye cuestiones tales como: ¿Cómo se distribuyen las ganancias de los empleados y trabajadores en los países europeos y en todo el mundo? ¿Las empleadas reciben menos salario que sus homólogos masculinos? ¿Son las personas más felices en algunos países y regiones del mundo que en otros lugares? ¿Ha aumentado la tasa de delincuencia en Alemania con la afluencia de refugiados? ¿Está engordando la humanidad? ¿Los jugadores de piel oscura en el fútbol europeo reciben más tarjetas rojas que sus compañeros de piel clara? ¿En qué condiciones es particularmente alta la contaminación urbana por polvo fino?

A continuación, se presenta un ejemplo que se centra en la unidad didáctica que investiga la calidad de la democracia, un tema central de la Estadística Cívica. Los materiales, aquí presentados en una versión adaptada con enfoque en América Latina, han sido probados en un seminario conjunto para estudiantes de segundo año de matemáticas y ciencias políticas que se preparan para ser maestros de secundaria. Los estudiantes de ambas asignaturas se mezclaron en grupos de trabajo y se les aconsejó que exploraran conjuntos de datos auténticos.

Los acontecimientos del pasado reciente - el éxito electoral de partidos con objetivos latentes o abiertamente antidemocráticos y la creciente polarización política- han proporcionado 
motivos para preocuparse por la estabilidad de la democracia en muchas regiones del mundo, incluso en las democracias supuestamente estables de occidente. Los líderes populistas están en aumento en muchos países, fabricando los hechos, usando chivos expiatorios y llamando a los periodistas responsables enemigos del pueblo. No solo los comentaristas periodísticos y escritores, sino también reconocidos politólogos diagnostican una transición a la posdemocracia (Crouch, 2004), evocan el peligro (Brown, 2019) y el posible fin (Runciman, 2018) de la democracia o el miedo - aún más preocupante - a su muerte (Levitzky \& Ziblatt, 2018). Por primera vez desde 2001, las democracias ya no son mayoría a escala mundial. El 54\% de la población mundial vive ahora en regímenes autocráticos que actualmente están establecidos en 92 países (V-dem institute, 2020, p. 6).

Estos diagnósticos de crisis plantean la cuestión de si la calidad de una democracia puede medirse utilizando datos estadísticos. De hecho, los politólogos han elaborado varios índices que permiten medir el estado de las democracias de forma comparable. Para poder medir la calidad de la democracia:

- En un primer paso, es necesario definir las características de la democracia (definición);

- Los indicadores empíricamente determinables deben derivarse de las características teóricamente definidas de la democracia (operacionalización);

- Es necesario determinar cómo se evalúan las características (cuantificación).

La plataforma Gapminder, creada por la Fundación Sueca Gapminder (https://www.gapminder.org/), ofrece recursos didácticos gratuitos con el objetivo de hacer que el mundo sea comprensible basándose en estadísticas fiables. Proporciona herramientas que visualizan más de 500 indicadores centrados en el desarrollo global sostenible, que son particularmente adecuados para el acceso de bajo umbral a las estadísticas cívicas. Varios indicadores y datos están relacionados con diferentes índices de democracia. Dos índices importantes son:

1. El indice del Polity Project (https://www.systemicpeace.org/polityproject.html): La democracia se define en este índice esencialmente a través de características institucionales. En particular, debe existir la posibilidad de influir en la formación del gobierno a través de elecciones; El ejercicio del poder por parte del gobierno debe ser 
limitado (separación de poderes) y deben existir derechos para las minorías. La escala de clasificación de los sistemas políticos va de -10 (monarquía hereditaria) a 10 (democracia consolidada). -10 significa sistemas máximamente autocráticos, 10 significa sistemas máximamente democráticos. Con una puntuación de 6 o más, el Center for Systemic Peace considera que un país es democrático.

2. El indice de Freedom-House (https://www.freedomhouse.org): La democracia está determinada en este indicador más allá de las características institucionales, por el grado de libertad de los ciudadanos. Por ejemplo, depende de un estado de derecho efectivo (protección de los derechos fundamentales) y de oportunidades para la participación política. La escala va de 1 (libertades máximas) a 7 (sin libertades). Un país se considera libre con una puntuación de 2,5 o menos. Nota técnica: Observe que la dirección de la escala cambió: mientras que para el índice Polity las puntuaciones altas indican una democracia liberal, el índice Freedom House identifica las democracias con una puntuación baja que va de 1 a 2,5.

Los datos de series de tiempo sobre el desarrollo de la democracia ofrecen un primer campo para los descubrimientos en estadísticas cívicas. El Polity Index es particularmente adecuado para esto, ya que los datos se recopilaron retrospectivamente hasta 1800 (una buena oportunidad para discutir críticamente la cuestión de la comparabilidad intertemporal de los datos con los estudiantes). Estos datos permiten localizar históricamente fases de democratización. Según la famosa tesis de Huntington (1991), la democratización se produce en oleadas. Esto significa que en ciertas fases hay aceleraciones transnacionales de democratización, seguidas de fases de consolidación y luego regresión (retroceso). Dentro de la primera ola larga, que comenzó en 1828 con la expansión del sufragio en Estados Unidos y finalizó en 1922 con la toma del poder de Mussolini en Italia, en América del Sur solo Colombia (1868-1885) y Costa Rica (desde 1876) se convirtieron en democracias (puntuación de 6 o más). Dentro de la segunda, que comenzó en 1943 con la caída de Mussolini y finalizó en 1962, Brasil (1946), Uruguay (1952), Colombia (1957), Venezuela (1958) y Jamaica (1959) se convirtieron en regímenes democráticos, los dos primeros, sin embargo, no pudieron estabilizarse. Fue solo en la tercera ola, que comenzó a mediados de la década de 1970 y disminuyó a fines de la de 1990, cuando la democracia en América Latina experimentó un impulso real: el número de 
democracias (con una Polity puntuación de 6 o más) aumentó de seis países en 1978 a 21 países en 2000 (ver Figura 4).

Figura 4. Tercera ola de democratización en América del Sur 1978-2000 (Polity Index)

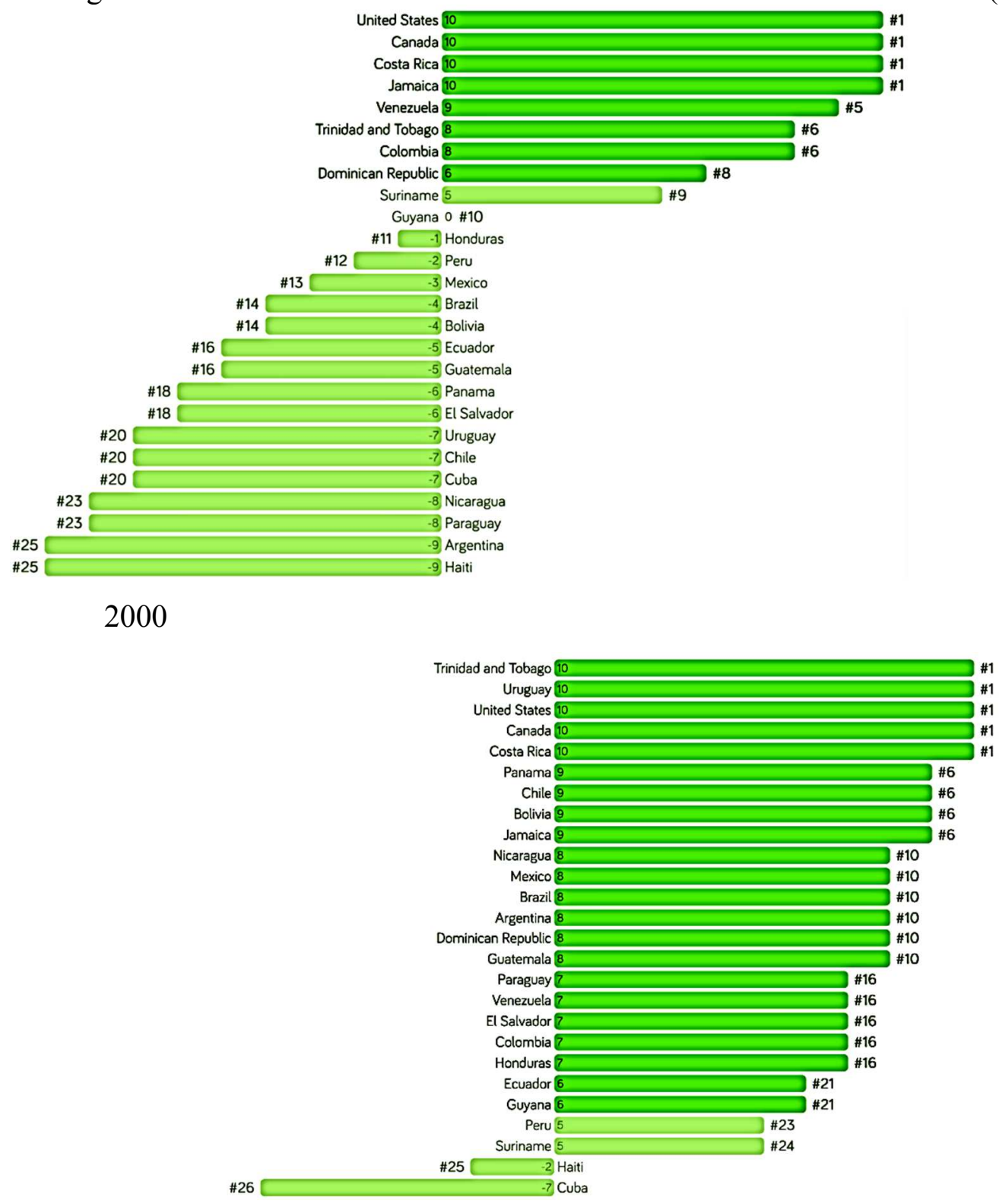

Fuente: Elaborado por los autores; Se destacan los regímenes democráticos con una puntuación de 6 o más.

Los críticos cuestionan la validez del Polity Index, con su enfoque en estructuras institucionales robustas que pueden registrarse retrospectivamente, por no capturar adecuadamente la realidad constitucional (por ejemplo, el grado en que los derechos fundamentales constitucionales están realmente garantizados). Para capturar esta dimensión de 
manera más adecuada, los índices basados en encuestas basados en calificaciones de expertos son más adecuados. ¿Puede confirmarse la tesis de una tercera ola de democratización de gran alcance en América Latina sobre la base de estos índices? En Gapminder, los estudiantes encontrarán varios índices para investigar esta pregunta sobre la base de la evidencia. El índice basado en encuestas más conocido y más utilizado es el índice Freedom House antes mencionado. Comparado con el índice Polity, se ve una correlación bastante alta (Figura 5).

Figura 5: Asociación entre dos índices de calidad de la democracia (Polity y Freedom House)
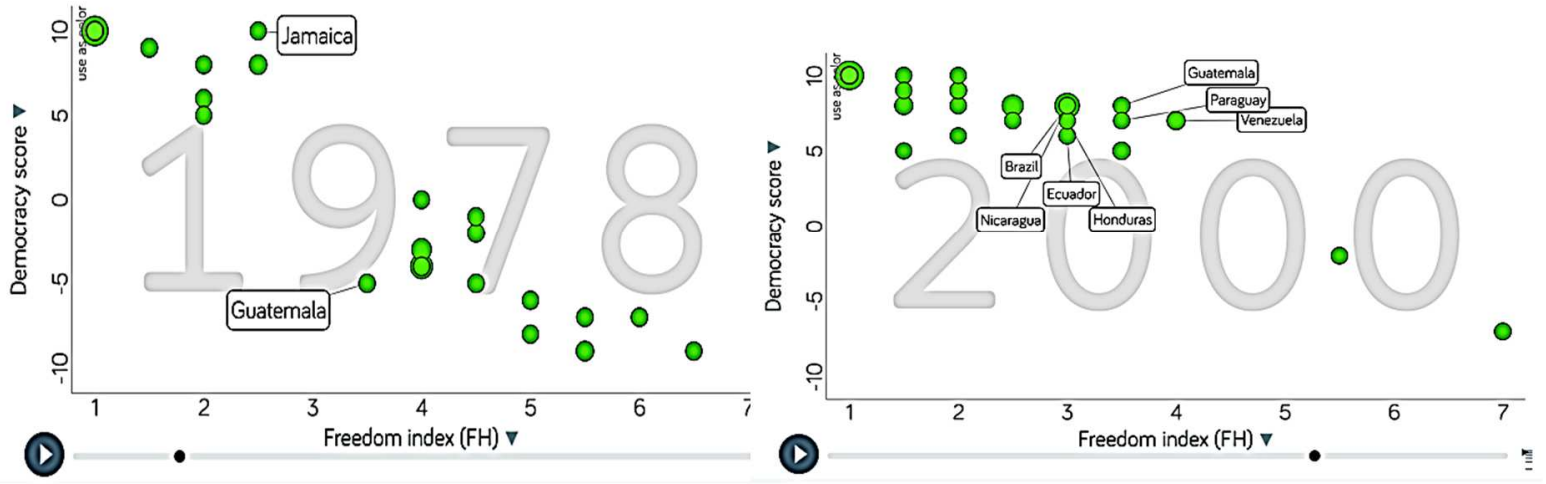

Fuente: Elaborado por los autores

En 1978 no hubo grandes discrepancias en la categorización: todos los regímenes democráticos según Polity (puntaje 6 o más) son también países libres (puntaje 2.5 o menos) según Freedom House. Los valores atípicos de la tendencia (aunque dentro de los valores de umbral) son Jamaica por un lado, que según Polity es una democracia perfecta (puntuación 10), pero en Freedom House está en el umbral de los países relativamente libres (2.5). Por otro lado, las valoraciones de Guatemala divergen, según Freedom House logrando un valor de libertad promedio (puntaje 3.5), mientras que según Polity está en la frontera de la autocracia (puntaje 5). En el año 2000 se puede ver que las burbujas se concentran en el parte superior izquierdo (Figura 5, lado derecho), lo que confirma la tesis de una ola de democratización. Un total de siete países que Polity clasifica como regímenes democráticos, sin embargo, son solo relativamente libres según Freedom House: Brasil, Nicaragua, Honduras, Ecuador, Guatemala, Paraguay y Venezuela.

A pesar de la impresionante confirmación general de la teoría de ondas de Huntington 
con respecto a América del Sur, los únicos resultados parcialmente consistentes (Polity vs. Freedom House) son una buena oportunidad para discutir cuestiones importantes que están en el corazón de las estadísticas cívicas. Desde un ángulo estadístico, se puede cuestionar cuán confiables son las categorizaciones de tipos de regímenes políticos (por ejemplo, democracia, anocracia, autocracia), si se basan en puntajes de umbral en escalas ordinales. Desde la perspectiva de las ciencias políticas, surge la pregunta de cómo deben fundamentarse las clasificaciones divergentes con miras a determinadas áreas del desempeño del sistema político. Aquí, es necesario mirar más allá de conceptos generales como democracia o libertad.

Si bien los índices globales adecuados como el Polity Index o el Freedom House Index sirven para comparar desarrollos de diferentes países a nivel general, con respecto a países particulares, se necesitan índices más específicos para obtener una comprensión más profunda de las transformaciones subyacentes. Desde el ángulo de las estadísticas cívicas, las cuestiones de la formación de índices y los niveles de agregación de datos pueden discutirse fructíferamente en este contexto. Esto se demostrará con una mirada especial a Colombia, un país que no parece estar perfectamente alineado con el movimiento general de olas desde 1978 en adelante (Figura 6). Contrariamente al auge de la democratización que comenzó en 1978, el grado de libertad de Colombia se estancó según Freedom House hasta fines de la década de 1980 en el espectro más bajo de un país libre (puntaje 2.5). Entre 1989 y 2004, Colombia se deterioró a un valor de escala de 4, antes de que volviera a producirse una leve mejora en 2004, lo que llevó a Colombia nuevamente al umbral de un país libre (puntuación 3).

Figura 6: Desarrollo del Índice de Libertad (Freedom House) en Colombia desde 1975

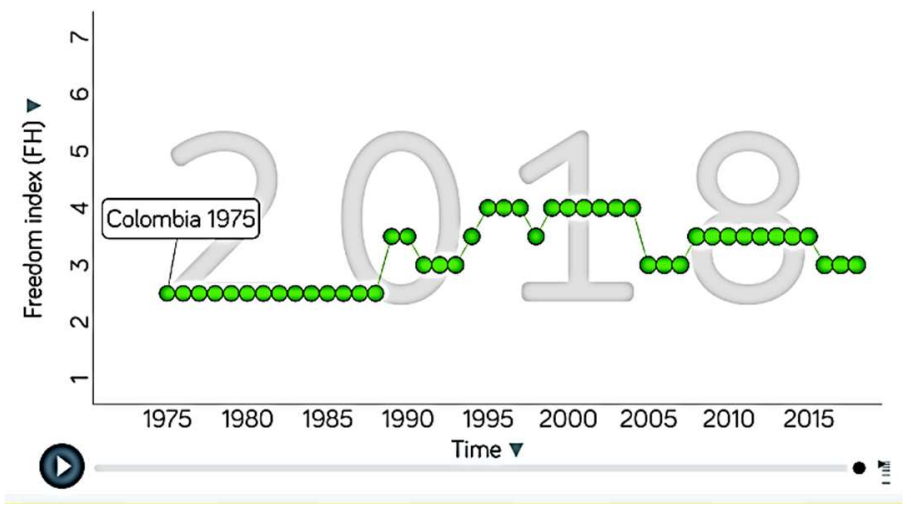

Fuente: Elaborado por los autores

Para comprender las transformaciones subyacentes, se puede utilizar una serie de índices más detallados que han sido desarrollados por el International Institute for Democracy and 
Electoral Assistance (International IDEA, https:/www.idea.int/es/índices-del-estado-global-dela-democracia) con sede en Estocolmo para evaluar la calidad de la democracia con mayor precisión. IDEA distingue entre cinco dimensiones del desempeño democrático (ver Figura 7): gobierno representativo, derechos fundamentales, control del gobierno, administración imparcial y compromiso de participación.

Figura 7: Cinco dimensiones de la democracia según IDEA

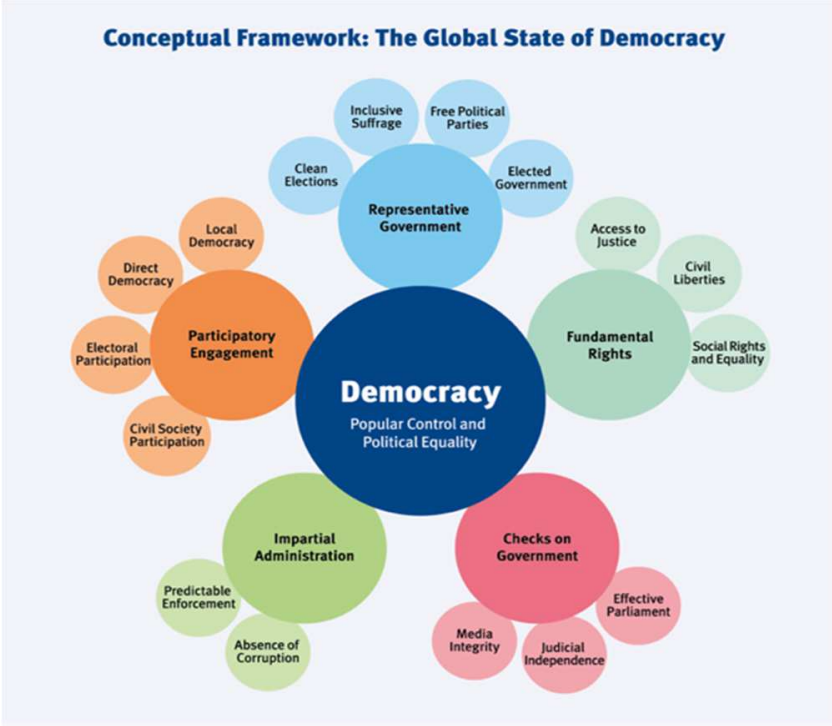

Fuente: https://www.idea.int/es/índices-del-estado-global-de-la-democracia

La dimensión gobierno representativo abarca la concepción de democracia electoral, según la cual los sistemas democráticos se basan en elecciones competitivas. Las elecciones libres con la elección de alternativas constituyen un consenso mínimo entre los teóricos de la democracia. Junto a las elecciones competitivas, la concepción de democracia liberal (Diamond 1999) se refiere a tres dimensiones más, que juntas constituyen el núcleo del estado constitucional liberal: primero, la garantía de los derechos fundamentales, segundo, la importancia de la separación de poderes, especialmente control efectivo del poder ejecutivo (controles del gobierno) y, en tercer lugar, la dimensión de la administración imparcial. La demanda de un compromiso participativo va más allá de las disposiciones de la democracia liberal y exige canales de participación que no se limiten a las elecciones, sino que abarquen una sociedad civil activa.

En el contexto de esta diferenciación entre las cinco dimensiones del desempeño democrático, los diferentes caminos de (des) democratización pueden analizarse de una manera más matizada. La aplicación de las cinco escalas antes mencionadas al desarrollo colombiano 
arroja los resultados mostrados en la Figura 8. Nota técnica: IDEA distinguió entre rendimiento bajo (0 a 39,9\%), rendimiento de rango medio (40 a 70\%) y alto rendimiento $(70,1$ a $100 \%)$.

Figura 8: Una visión más cercana del desarrollo colombiano

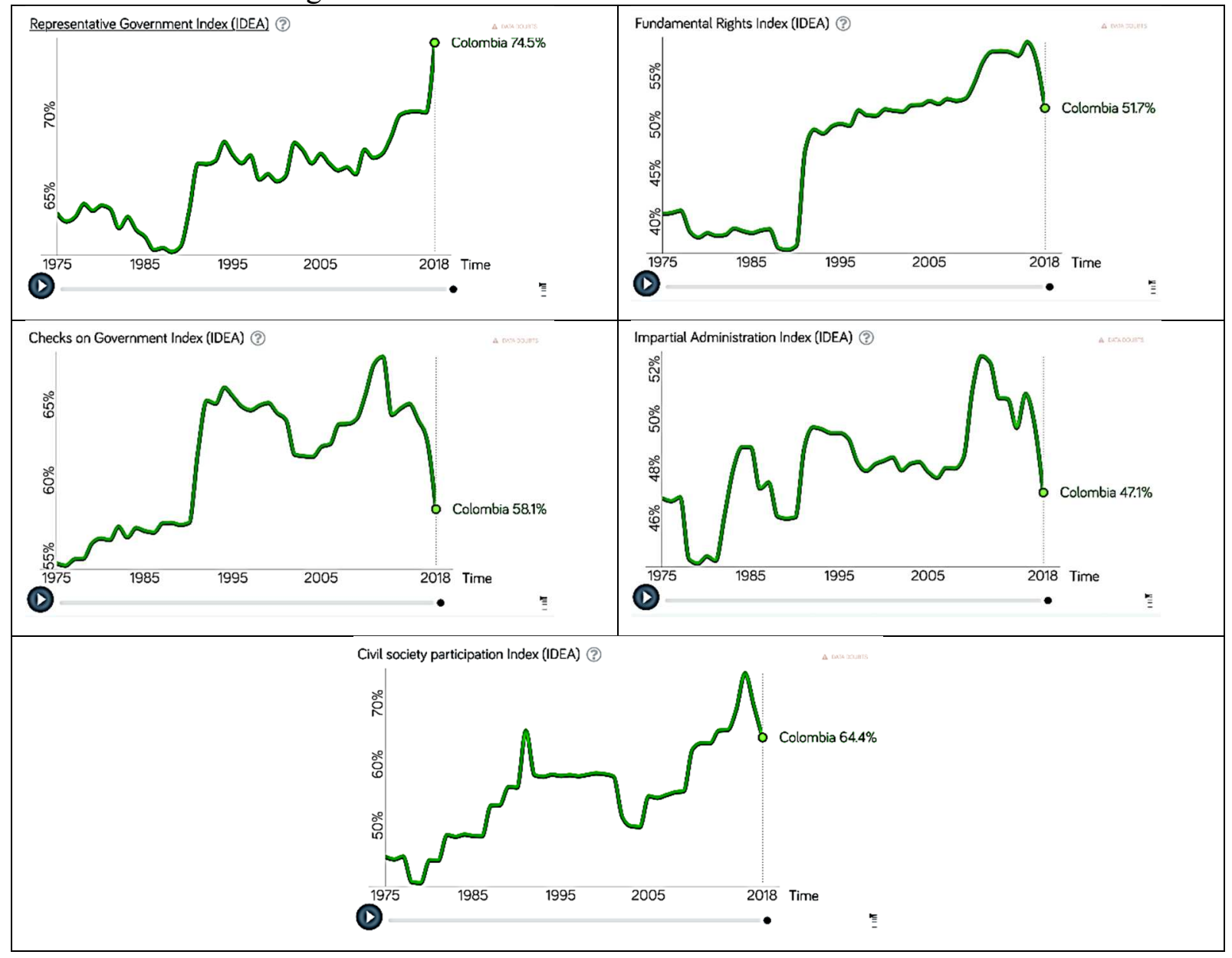

Fuente: Elaborado por los autores

Los índices muestran que el leve deterioro en la calidad de la democracia desde 1989, señalado por Freedom House como una tendencia general, no es discernible en todas las dimensiones cubiertas por IDEA: Si bien los avances en la dimensión de la democracia electoral han continuado desde finales de los años ochenta e incluso acelerado en los últimos tiempos (Colombia se cuenta ahora entre las democracias de alto desempeño en este sentido), se pueden ver regresiones en las otras dimensiones, especialmente en lo que respecta a los controles de los poderes ejecutivos en el gobierno y la administración. Los datos reflejan, entre otras cosas, el hecho de que la posición constitucionalmente fuerte del presidente se ha fortalecido nuevamente desde una reforma en 2003. Además, ha habido una disminución en la protección de los 
derechos fundamentales desde 2016, que a primera vista puede ser una sorpresa, ya que este año se firmó un tratado de paz entre el gobierno y el principal grupo guerrillero de izquierda de Colombia, luego de conflictos armados que se habían mantenido a fuego lento durante décadas. La disminución de la puntuación de los derechos fundamentales arroja luz sobre el hecho de que el país aún enfrenta enormes desafíos para consolidar la paz. Para una imagen más completa, se deben discutir más aspectos (aunque no se puede hacer dentro del alcance de este artículo). Los numerosos índices de IDEA disponibles en Gapminder ofrecen la oportunidad de realizar evaluaciones detalladas y discusiones enriquecedoras basadas en evidencia.

Otra pregunta interesante es cómo se relaciona la calidad de la democracia con otras variables estadísticas cívicas. Puede resultar revelador investigar las correlaciones con otras características de las sociedades modernas. En el seminario, se animó a los estudiantes a formular y justificar hipótesis y luego explorar los datos de forma independiente. Vale la pena informar de dos hallazgos. El primero se basa en una correlación entre el nivel de desarrollo económico (PIB per cápita) y la calidad de la democracia (Freedom House). Se puede observar una correlación bastante alta, solo Cuba forma una excepción con un nivel promedio de prosperidad bajo un régimen político autoritario (ver Figura 8). Este hallazgo es consistente con la literatura clásica que enfatiza la importancia de los prerrequisitos estructurales para la democratización (Lipset, 1959; 1993; con un enfoque en América del Sur: Abente, 2007).

Sin embargo, es importante advertir a los estudiantes contra la interpretación excesiva de sus hallazgos. Se recomienda precaución aquí, no apresurarse a disparar a la causalidad incluso con fuertes correlaciones estadísticas. La causalidad está asociada con desafíos filosóficos sofisticados que van mucho más allá de simples mantras como La correlación no implica necesariamente causalidad (Pearl \& Mackenzie 2016). Los datos de las ciencias sociales provienen principalmente de estudios de observación, encuestas o datos de archivo y rara vez de estudios experimentales. Como resultado, a menudo es difícil identificar de manera confiable las relaciones de causa y efecto.

A pesar de esta salvedad, la exploración de las relaciones causales es de gran importancia para comprender y teorizar. La correlación varía con el tiempo (lo que se puede mostrar muy bien presionando el botón play en la herramienta Gapminder) y es posible que no se mantenga cierta durante un período de tiempo más largo. Además, cierto nivel de desarrollo económico puede ser útil para países al borde de la democratización, pero puede que no fomente el 
desempeño democrático más allá de cierto punto (Mainwaring \& Pérez-Liñán 2003).

Figura 8: Asociación entre la calidad de la democracia (según el índice de libertad) y el nivel de desarrollo económico (PIB per cápita)

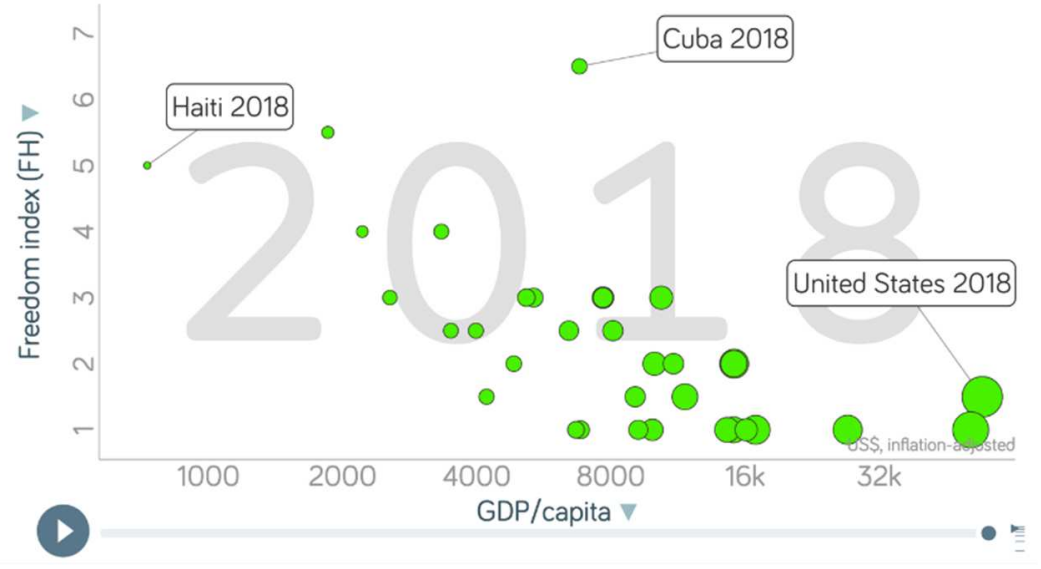

Fuente: Elaborado por los autores

Otro hallazgo se muestra en la Figura 9, que muestra el índice Freedom House versus el índice de percepción de corrupción (IPC). El IPC, creado por Transparencia Internacional (https://www.transparency.org/en/cpi), califica y clasifica a los países en función de qué tan corrupto es percibido el sector público de un país por los expertos y ejecutivos de empresas. Es un índice compuesto, una combinación de 13 encuestas y evaluaciones de corrupción, recopiladas por una variedad de instituciones acreditadas. Las pistas más altas indican menos corrupción. El IPC es el indicador de corrupción más utilizado en todo el mundo.

Los datos muestran que en la mayoría de los países un índice de libertad bajo (país muy libre) significa un índice de percepción de la corrupción alto (poca corrupción percibida) y viceversa. Sin embargo, el IPC no disminuye sistemáticamente con el índice Freedom House. Entonces, no hay países relativamente libres (puntaje 2) pero que aún tengan un IPC alto. Jamaica, que cuenta como un país libre (puntaje 2.5), obtiene un puntaje casi tan alto en el IPC como Cuba (puntaje 44 vs. 47). Y los países libres como Santa Lucía (puntuación 1) o Granada (puntuación 1,5) tienen altas puntuaciones en IPC (de 55 y 52). - Dado que los datos del IPC solo están disponibles desde 2012, se pueden ver pocos movimientos.

Figura 9: Asociación entre calidad de la democracia (índice de Libertad) y corrupción (IPC). 


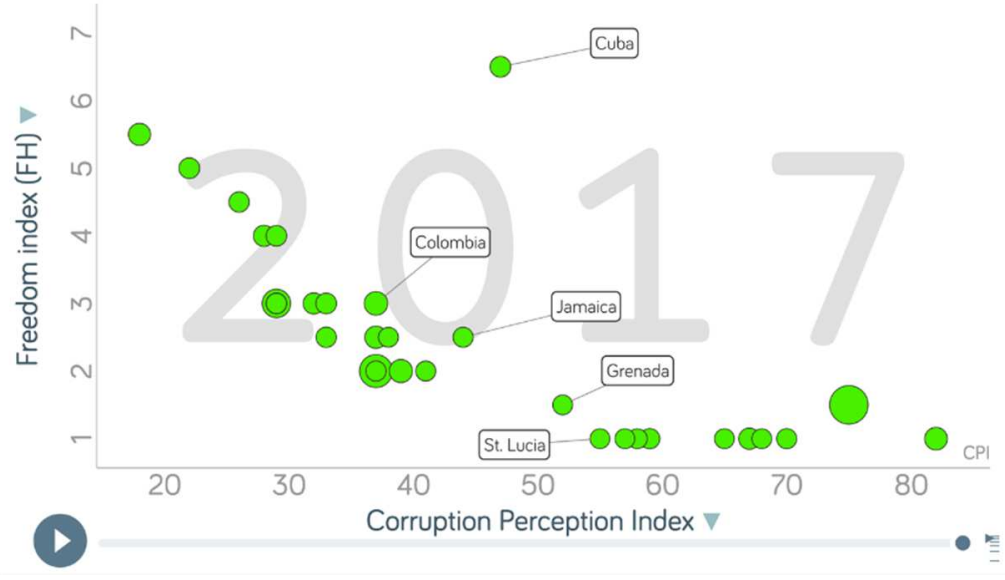

Fuente: Elaborado por los autores

El Índice de Libertad incluye tanto los derechos políticos como las libertades civiles. Un país democrático tiene muchas características como la separación de poderes y el estado de derecho, que influyen en estos parámetros y permiten combatir la corrupción. Esta podría ser una de las razones que explica la correlación entre estos índices. Una vez más, se debe aumentar la conciencia crítica de los estudiantes. A pesar de su uso generalizado, el indicador IPC no es indiscutible. Dado que el IPC describe la corrupción percibida, no es un indicador directo de la corrupción real. La sospecha de corrupción podría estar relacionada con la falta de confianza en las élites gobernantes, que probablemente sea menor en las autocracias que en las democracias. Una discusión de estas críticas se desarrolla en Lambsdorff (2006).

\section{Implicaciones curriculares: necesidad de nuevos recursos didácticos}

En este trabajo argumentamos que, en las democracias modernas, el compromiso ciudadano efectivo con los problemas sociales requiere una participación activa, y que esto a su vez requiere, entre otras cosas, una amplia gama de habilidades y disposiciones relevantes para comprender los datos y las estadísticas sobre los problemas sociales. Esta realidad requiere repensar la naturaleza de la educación estadística en escuelas y universidades (Cobb, 2015). Dado que la estadística cívica se encuentra en la encrucijada de múltiples disciplinas, se necesita una perspectiva educativa multidisciplinaria que salga de la zona de confort de la educación estadística tradicional (ProCivicStat, 2018; Ridgway, 2021, de próxima publicación).

La enseñanza de la estadística en los niveles primario y secundario la realizan con mayor frecuencia profesores de matemáticas, y la investigación sugiere que muchos profesores de 
matemáticas, y de otras disciplinas, no están adecuadamente preparados para enseñar estadística o habilidades relacionadas con los datos de manera eficaz (Batanero et al., 2011; Franklin et al., 2015). Muchos profesores de matemáticas que tienen la tarea de enseñar conceptos estadísticos y otros conceptos relacionados con los datos a menudo carecen tanto del conocimiento del contenido como del conocimiento pedagógico para respaldar una comprensión profunda de los conceptos estadísticos básicos y las formas de pensar con datos (Hannigan et al., 2013). En esencia, la mayoría de los planes de estudios de estadística se centran en problemas de una sola variable (o quizás dos); se centran en el dominio técnico de las técnicas matemáticas desarrolladas hace más de 100 años; utilizan datos artificiales; y hacen poco uso de las técnicas de visualización de datos. Las técnicas estadísticas enseñadas no están alineadas con las necesidades de la ciudadanía y no están orientadas a permitir que los estudiantes transfieran las habilidades que adquieren a sus deberes como ciudadanos comprometidos.

Las competencias y los contenidos descritos no se pueden delegar a una sola disciplina o asignatura en la escuela. Dar sentido a los datos también es parte de la enseñanza en geografía, historia, cívica y economía, así como en biología y física. En las escuelas secundarias, pocos profesores de matemáticas o ciencias sociales reciben formación sobre cómo enseñar estadística (Batanero, et al., 2011). Como resultado, los profesores de matemáticas pueden permanecer dentro de su zona de confort y hacer demasiado hincapié en una gama limitada de técnicas y cálculos estadísticos, mientras que los profesores de ciencias sociales pueden eludir los enfoques cuantitativos casi por completo. En todo el plan de estudios se presta muy poca atención a trabajar y comprender datos multivariados que describen tendencias sociales, o al análisis, interpretación y comunicación sobre el significado de dichos datos.

Un aspecto central de las estadísticas cívicas son las cuestiones de interés público relacionadas con el bienestar social y económico de todos los ciudadanos y el funcionamiento de la democracia. Esto impone grandes exigencias a los instructores, ya que los profesores de educación cívica y geografía necesitan más que un conocimiento básico de estadística descriptiva: requieren conocimientos más profundos y una base de contenido pedagógico estadístico. Los profesores de matemáticas deben ser capaces de interpretar los resultados de las representaciones y análisis estadísticos en el contexto social y facilitar las discusiones sobre temas controvertidos en el aula. La enseñanza interdisciplinaria debe enfatizar el interés en temas candentes relacionados con el bienestar social y económico y la realización de los 
derechos civiles.

Las matemáticas proporcionan un conocimiento analítico importante y transmite ciertos métodos y representaciones de análisis de datos exploratorios, como diagramas de dispersión o diagramas de caja, introduce conceptos como distribución, correlación, regresión, variables de confusión explicativas, etc. y discute cómo se pueden obtener nuevos conocimientos cambiando varios valores numéricos. y formas gráficas de representación. La educación en ciencias de la computación podría proporcionar una posible función integradora para el plan de estudios escolar en el contexto de un plan de estudios de ciencia de datos.

Pero las estadísticas cívicas tratan fundamentales de las cuestiones de interés público relativas al bienestar social y económico de todos los ciudadanos y al funcionamiento de la democracia. Afortunadamente, existen herramientas digitales diseñadas pedagógicamente como Fathom, CODAP o iNZight, así como visualizaciones en Internet como Gapminders o animaciones en las páginas web de estadísticas oficiales, que permiten a los estudiantes explorar datos sociales multivariados de forma innovadora.

Los análisis del proyecto ProCivicStat apuntan a las deficiencias y problemas de la educación actual en estadística en escuelas y colegios. Para ayudar a los jóvenes a participar de manera competente e informada en los debates públicos sobre problemas sociales y hacerlos participar en la resolución de problemas candentes, consideramos que los cambios curriculares en la forma en que se enseñan las estadísticas en las escuelas son necesarios. El análisis de datos, la interpretación de gráficos y las visualizaciones (dinámicas) no solo están relacionados con el conocimiento matemático, sino que son parte del conocimiento adquirido en muchas materias y, por lo tanto, deberían formar parte de un ámbito más amplio de disciplinas.

Las estadísticas cívicas requieren un enfoque de enseñanza diferente al de las estadísticas tradicionales, por lo que se necesita más que una lista de recursos. Los recursos desarrollados por ProCivicStat están disponibles gratuitamente (http://iase-web.org/islp/pcs) y ofrecen tanto recursos como sugerencias para secuencias de instrucción que se coordinan a través de un marco conceptual general de las bases de conocimiento y las habilidades asociadas con Estadísticas cívicas. Los planes de lecciones y las actividades de clase dejan en claro qué facetas del marco conceptual de ProCivicStat están vinculadas o pretenden mejorar. De manera similar, los conjuntos de datos y las actividades de análisis de datos están diseñados con una conexión directa y clara con un problema social y están integrados en un contexto social relevante. 
La Estadística Cívica tiene un papel importante que desempeñar en el apoyo al proceso democrático y en la mejora de la toma de decisiones en todos los niveles, desde el personal hasta el local, nacional e internacional. La descripción y el desarrollo de las competencias necesarias para manejar la evidencia evolucionarán a medida que surjan diferentes problemas y diferentes tipos de datos. El desarrollo de habilidades en Estadística Cívica es un viaje para disfrutar, no un destino para alcanzar.

\section{Referencias}

Abente Brun, D. (2007). The quality of democracy in small south american countries: The case of Paraguay. Kellogg Institute Working Paper \#343 (November). South Bend, I: University of Notre Dame. https://kellogg.nd.edu/documents/1651.

Batanero, C, Burrill, G., \& Reading, C. (2011). Teaching statistics in school mathematics: challenges for teaching and teacher education. 18th Study of the International Commission on Mathematical Instruction. Heidelberg: Springer:

Ben-Zvi, D. \& Garfield, J. (2004). Statistical literacy, reasoning, and thinking: goals, definitions, and challenges. In D. Ben-Zvi \& J.Garfield (Eds.), The challenge of developing statistical literacy, reasoning, and thinking (pp. 3-15). Dordrecht, The Netherlands: Kluwer.

Borovcnik, M., \& Ossimitz, G. (1987). Materialien zur Beschreibenden Statistik und Explorativen Datenanalyse. Wien, Austria: Hölder-Pichler-Tempsky.

Brodie, E. Hughes, T. Jochum, V. Miller, S. Ockenden, N. \& Warburton, D. (2011). Pathways through participation: What creates and sustains active citizenship? UK: Authors. http://www.sharedpractice.org.uk/Downloads/Pathways summary report.pdf.

Brown, J. (2019). Democracy in danger. How cyberthreats undermine election in America. Toronto: Rowman \& Littlefield.

Cobb, $\mathrm{G}$ (2015). Mere renovation is too little too late: We need to rethink our undergraduate curriculum from the ground up, The American Statistician, 69(4), 266-282, https://doi.org/10.1080/00031305.2015.1093029.

Condorcet, A. (1994): Foundations of social choice and political theory. Brookfield, VT: Edward Elgar (Original work published in 1792).

Crouch, C (2004). Post-democracy. New York: Wiley \& Sons

Diamond, L (1999). Developing democracy. Toward consolidation. Baltimore: John Hopkins University Press.

Eckstein, D., Künzel, V., Schäfer, L. \& Winges, M. (2019). Global climate risk index 2020. Who suffers most from extreme weather events? Weather-related loss events in 2018 and 1999 to 2018. Berlin: Germanwatch. https://www.germanwatch.org/es/17307.

Engel, J. (2017). Statistical literacy for active citizenship: A call for data science. Statistics Education Research Journal, 16(1), 44-49. 
Engel, J. (2019). Cultura estadística y sociedad. En J. M. Contreras, M. M. Gea, M. M. LópezMartín y E. Molina-Portillo (Eds.), Actas del Tercer Congreso Internacional Virtual de Educación Estadística. www.ugr.es/local/fqm126/civeest.html

Fischer, R. (1984). Offene Mathematik und Visualisierung, Mathematica Didactica 7, 139-160.

Freire, P. (2014). Pedagogy of the oppressed. 30th Anniversary Edition. New York: Bloomsbury Publishing.

Gal I. (2002) Adults‘ statistical literacy: meanings, components, responsibilities. International Statistical Review, 70(1), 1-51. https://doi.org/10.1111/j.1751-5823.2002.tb00336.x

Gigerenzer, G. (2014). Risk savvy: How to make good decisions. New York: Viking.

Hannigan, A., Gill, O., \& Leavy, A. M. (2013). An investigation of prospective secondary mathematics teachers' conceptual knowledge of and attitudes towards statistics. Journal of Mathematics Teacher Education, 16(6), 427-449. https://doi.org/10.1007/s10857-0139246-3.

Huntington, S. P. (1991). Democracy's third wave. Journal of democracy 2(2), 12-34.

Lambsdorff, J. G. (2006). Measuring corruption. The validity and precision of subjective indicators. En C. Sampford et al. (Ed.), Measuring corruption (pp. 81-100). Aldershot, UK: Ashgate Publishing.

Lesser, L. (2007). Critical values and transforming data: Teaching statistics with social justice. Journal of Statistics Education, 15(1), 1-21.

Levitsky, S. \& Ziblatt, D. (2018). How democracies die. New York: Crown.

Lipset, S.M. (1959). Some social requisites of democracy: Economic development and political legitimacy. American Political Science Review, 58, 69-105.

Lipset, S.M. (1993). The social requisites of democracy revisited. American Sociological Review, 59, 1-22.

López-Martín, M., Batanero, C., \& Arteaga, P. (2016). Using united nation data in the training of teachers to teach statistics. In: J. Engel (Ed.), Promoting understanding of statistics about society. Proceedings of the Roundtable Conference of the International Association of Statistics Education (IASE), July 2016, Berlin, Germany.

Louie, J., Chance, B., Roy, S., Fagan, E., \& Stiles, J. (2020). Building statistical thinking with social justice investigations and social science data. Presented at the Society for Research on Educational Effectiveness Spring 2020 Virtual Conference.

Mainwaring, S. \& Pérez-Liñán, A. (2003). Level of development and democracy. Comparative Political Studies 36(9), 1031-1067.

Neurath, O. (2010). From hieroglyphics to isotype: A visual autobiography. London: Hyphen Press.

Nicholson, J., Gal, I., \& Ridgway, J. (2018). Understanding civic statistics: A conceptual framework and its educational applications. A product of the ProCivicStat Project. http://IASE-web.org/islp/pcs

Nowotny, H. (2016). A scientific outlook for a post-factual world. Project syndicate. The 
world's opinion page. http://www.project-syndicate.org/commentary/science- uncertaintypost-factual-world-by-helga-nowotny-2016-11

OECD (2009) Focus on citizens: Public engagement for better policy and services. Online https://www.oecd-ilibrary.org/governance/focus-on-citizens 9789264048874-en

Pearl, J. \& Mackenzie, D. (2016). The book of WHY. The new science of cause and effect. London: Penguin.

Playfair, W. (2005). The commercial and political atlas and statistical breviary. Cambridge: Cambridge University Press. (trabajo original publicado en 1786).

ProCivicStat Partners (2018). Engaging civic statistics: A call for action and recommendations. A product of the ProCivicStat Project. http://IASE-web.org/ISLP/PCS

Ridgway, J., Nicholson, J., \& Gal, I. (2017). Task analysis tool: Facets of statistical literacy. Document supporting the ProCivicStat Workshop conducted at the IASE Satellite Conference, Rabat 11-13 July.

Ridgway, J. ( 2021). Teaching statistics for empowerment and social engagement. New York: Springer:

Runciman, D. (2018). How democracy ends. Profile Books.

Skovsmose, O. (1994). Towards a critical mathematics education. Educational Studies in Mathematics, 27 (1), S. 35-57. https://doi.org/10.1007/BF01284527.

Steen, L. (2001). Mathematics and democracy: The case for quantitative literacy. New York: The National Council on Education and the Disciplines,

V-dem institute (2020). Autocratization surges, resistance grows. Democracy report 2020. https://www.v-dem.net/media/filer_public/de/39/de39af54-0bc5-4421-89aefb20dcc53dba/democracy report.pdf.

Wallman K (1993) Enhancing statistical literacy: Enriching our society. Journal of the American Statistical Association, 88(421), 1-8.

Weiland, T. (2017) Problematizing statistical literacy: An intersection of critical and statistical literacies. Educational Studies in Mathematics, (96), 33-47. DOI 10.1007/s10649-0179764-5.

\section{Autores}

\section{Joachim Engel}

Profesor de matemáticas y educación matemática en la Universidad de Educación de Ludwigsburg, Alemania. Con un doctorado en Matemáticas Aplicadas de la Universidad del

Sur de California (USC), sus intereses de investigación son el modelado matemático, la estadística y la probabilidad y su enseñanza y aprendizaje. Actualmente, es Presidente de la International Association for Statistical Education (IASE). E-mail: engel@ph-ludwigsburg.de.

\section{Jim Ridgway}


Profesor emérito de la Escuela de Educación de la Universidad de Durham, Reino Unido. Psicólogo cognitivo de formación, su extenso historial de investigación se centra en psicología educativa, psicología matemática, resolución de problemas y uso de ordenadores. $\mathrm{Su}$ investigación más reciente se centra en el razonamiento con evidencia, visualización de datos, pensamiento y resolución de problemas, cuestiones de equidad y cambio educativo. E-mail: jim.ridgway@durham.ac.uk

Florian Weber-Stein

Profesor de ciencias políticas en la Universidad de Educación de Ludwigsburg, Alemania. Obtuvo su doctorado con una tesis sobre la importancia de las emociones para la sociología de Max Weber en la Universidad de Jena y ha trabajado como profesor de secundaria durante tres años. Sus áreas de investigación de especial interés incluyen la teoría de la democracia y las concepciones innovadoras de la educación en ciencias políticas. E-mail: Florian.weber-stein@ph-ludwigsburg.de 